\title{
Spatial Inequality Hides the Burden of Dog Bites and the Risk of Dog-Mediated Human Rabies
}

\author{
Micaela De la Puente-León, ${ }^{1}$ Michael Z. Levy, ${ }^{1,2}$ Amparo M. Toledo, ${ }^{1}$ Sergio Recuenco, ${ }^{3}$ Julianna Shinnick, ${ }^{2}$ and \\ Ricardo Castillo-Neyra ${ }^{1,2 *}$ \\ ${ }^{1}$ Zoonotic Disease Research Laboratory, One Health Unit, School of Public Health and Administration, Universidad Peruana Cayetano Heredia, \\ Arequipa, Perú; ${ }^{2}$ Department of Biostatistics, Epidemiology and Informatics, University of Pennsylvania, Philadelphia, Pennsylvania; ${ }^{3}$ Centro de \\ Investigaciones Tecnológicas, Biomédicas y Medioambientales, Universidad Nacional Mayor de San Marcos, Lima, Perú
}

\begin{abstract}
Since its reintroduction in 2015, rabies has been established as an enzootic disease among the dog population of Arequipa, Peru. Given the unknown rate of dog bites, the risk of human rabies transmission is concerning. Our objective was to estimate the rate of dog bites in the city and to identify factors associated with seeking health care in a medical facility for wound care and rabies prevention follow-up. To this end, we conducted a door-to-door survey with 4,370 adults in 21 urban and 21 periurban communities. We then analyzed associations between seeking health care following dog bites and various socioeconomic factors, stratifying by urban and peri-urban localities. We found a high annual rate of dog bites in peri-urban communities (12.4\%), which was 2.6 times higher than that in urban areas (4.8\%). Among those who were bitten, the percentage of people who sought medical treatment was almost twice as high in urban areas (39.1\%) as in peri-urban areas (21.4\%).
\end{abstract}

\section{INTRODUCTION}

Arequipa, an Andean city of approximately one million people, has grown continuously over the past six decades. ${ }^{1,2}$ The population growth of the city has been sustained by migration, mostly from the countryside. ${ }^{3}$ The expansion of the city has occurred outwardly from the city center to the peripheral areas, as is the case in many South American cities. ${ }^{1,4,5}$ Therefore, a centrifugal urbanization gradient that differentiates urban and peri-urban areas can easily be observed in the urban landscape in Arequipa. ${ }^{5}$ There is also a geographical stratification of resources, including access to social services, health care, and educational opportunities, a phenomenon known as "spatial inequality."

Rabies was reintroduced to the dog population of Arequipa in $2015 .^{7,8}$ Continuous transmission of the rabies virus, with one new case per week in 2019 and the beginning of 2020, indicates that the area is endemic once again. The risk of acquiring rabies is influenced by exposure to dog bites from dogs with the disease and access to treatment following exposure. Ninety-nine percent of human rabies deaths worldwide can be attributed to dog-mediated infections. ${ }^{9}$ Human rabies has not been detected in Arequipa since $1990 .{ }^{10}$ However, human dog bites are ongoing in Arequipa; therefore, the risk for human rabies cases is presumably significant. Also, because clinical rabies diagnostics in humans is a difficult and complex task, some cases could die undetected by the system. ${ }^{11,12}$ Following the reintroduction of rabid dogs in 2015, the annual number of dog bites increased from 2,599 in 2014 to 6,621 in 2015 and 10,332 in 2016. ${ }^{13,14}$ This increase is likely due to an increase in awareness and reporting following citywide efforts to disseminate information about rabies prevention. Nonetheless, the number of bites not reported to the health system is unknown and is a threat to the rabies control program in Peru. Hundreds of rabid dogs have been detected since the beginning of the outbreak, and virtually every district of the city has had at least one case. ${ }^{15-18}$

Rabies is invariably a lethal disease, but it is also preventable. ${ }^{19,20}$ The most effective strategy for human rabies

\footnotetext{
*Address correspondence to Ricardo Castillo-Neyra, Department of Biostatistics, Epidemiology and Informatics, University of Pennsylvania, 423 Guardian Drive, Philadelphia, Pennsylvania, E-mail: cricardo@ upenn.edu
}

prevention is to act on the animal reservoir, using mass dog vaccinations to stop transmission. ${ }^{21-24}$ However, when people are bitten by dogs in areas with active transmission of rabies virus, rabies prophylaxis is necessary. ${ }^{25}$ In Arequipa and other dog rabies-endemic areas around the world, people must receive medical treatment when attacked by rabid reservoirs or potentially rabid animals.

Medical treatment for rabies includes wound management and rabies postexposure prophylaxis (PEP), consisting in the administration of rabies immunoglobulin and a series of rabies vaccines provided when a person is attacked by rabid reservoirs or potentially rabid animals. ${ }^{20,26}$ Postexposure prophylaxis is effective at protecting those exposed to rabies virus, ${ }^{27}$ but timely wound management is crucial. ${ }^{9}$ Wound management consists of cleaning the wound with soap and water, identifying the dog, and seeking attention at the nearest health facility; in some cases, equine rabies immunoglobulin is required. ${ }^{27,28}$ Nearly 1 million people potentially exposed to rabies received PEP treatment annually just in the Americas. ${ }^{29}$ However, dog bite victims typically neglect treating their wounds appropriately, if at all, and many fail to seek medical treatment. ${ }^{30-34}$ In addition to the number of infected dogs, lack of access to appropriate medical treatment for rabies can also increase the risk of human rabies.

There are a greater number of free-roaming dogs in peri-urban than urban areas of Arequipa. Among these animals, there is a higher rate of rabid dogs detected in peri-urban areas that are more likely to bite and expose people to the virus. Given these two facts, we hypothesized that dog bites in peri-urban Arequipa are underreported. Therefore, we conducted a communitybased survey in urban and peri-urban areas of the city of Arequipa. Our objectives were to estimate the dog bite rates in peri-urban and urban Arequipa and identify spatial and social factors associated with seeking health care following a dog bite incident. The results of this study provide information about spatial inequality in human rabies risk in Arequipa and insights into implementation of community strategies to improve both dog rabies surveillance and rabies healthcare access.

\section{METHODOLOGY}

Ethics statement. Ethical approval was obtained from Universidad Peruana Cayetano Heredia (approval number: 65369), Tulane University (approval number: 14-606720), 
and the University of Pennsylvania (approval number: 823736).

Study setting. This study was conducted in the Alto Selva Alegre (ASA) district of Arequipa (human population in 2016: $83,310)$, one of the city's 14 districts. ${ }^{13}$ Arequipa, Peru's second largest city, is home to 969,000 people. The city of Arequipa comprises communities spanning different stages of urbanization and different migration histories, from neighborhoods established at the beginning of the twentieth century to recent developments. ${ }^{5}$ Within this gradient of development, most of the recently settled neighborhoods are located on the periphery of the city (peri-urban area) and the older localities are nearer to the center (urban area). ${ }^{5}$ Compared with urban areas of the city, peri-urban areas generally have distinct geographic features, with rugged and uneven terrain (Figure 1). They are also marked by unique social characteristics, which include lower socioeconomic status, fewer community resources, and higher crime rates than urban areas (Figure 1). As newer neighborhoods mature into established neighborhoods with wealthier residents, homes are improved with better quality construction material and permanent utility connections, and connectivity with the rest of the city increases with better sidewalks, roads, and transportation access. The ASA district transects the city, running from the center to the periphery and was, therefore, chosen as our study site because it encompasses both urban and periurban areas. Within the ASA district, the study sites include 21 urban neighborhoods founded multiple decades ago and 21 peri-urban neighborhoods that originated around the year 2000 or later (Figure 1).

Data collection. In September 2016, our team visited all the houses in selected neighborhoods of ASA-6,420 housesduring the survey period. In total, 1,889 houses were located in peri-urban areas and 4,531 in urban areas. In all, 4,370 community members (each for a unique household) consented to participate in the study and were surveyed. Participation was $29.8 \%$ and $84.0 \%$ in peri-urban areas and urban areas, respectively. Surveys were performed door-to-door and lasted approximately 25 minutes. They contained questions regarding family composition of the household, dogs in the house, the interviewee's sociodemographic information, dog bite incidents, and people's actions following dog bite incidents. Each interview was of one adult, usually the person who answered the door. All houses were previously georeferenced by our team for other studies.

We also georeferenced all health posts and centers in Arequipa city. This includes 88 health facilities in total ( 30 health centers and 58 health posts), six of them are located in ASA (three health centers and three health posts). No new health facilities have been built in ASA in the last decade, ${ }^{31}$ and there are no hospitals in the ASA district. We then calculated the shortest route from the households to the nearest health facility by foot. This approach assumed that community members would choose to go to the nearest public health facility and was not necessarily the actual route followed by those who sought care or the routes that those who did not seek care would have taken. Participants were asked if they sought care but not about the location of the health facility they visited and if it was public or private, or the level of the health facility (post, health center, clinic, hospital, etc.).

The sociodemographic information we obtained from the dog bite survey included gender, age, and educational attainment. We also gathered household data including the total number of people in the household, number of people younger than 18 years (the age of majority in Peru), number of children younger than 5 years, time living in the area, and number of dogs living in the house. The number of years that the interviewee had lived in their house was used as a proxy for time living in the area. We also registered the ownership status (own or unknown dog) and vaccination status of the dog that bit the participant. If the person did not know the vaccination status of the dog that bit them, we considered the dog to not be vaccinated, as is standard in local and international procedures to apply PEP in those cases. ${ }^{28,32}$

Statistical analysis. We collected data from bitten adults only, as they are capable of making a decision about whether or not to seek medical care. We also calculated the shortest distance from the house to the nearest health facility using Leaflet, an open-source JavaScript library for interactive maps that can calculate routes by car, bike, public transportation, and walking. ${ }^{33}$ We set each bitten person's house as a starting point and each health facility in Arequipa as an endpoint, via Leaflet Routing Machine services and Mapbox Directions API, and then we calculated the shortest walking distance.

We explored the spatial distribution of the bite cases and health facilities in urban and peri-urban areas. To evaluate the characteristics of interviewees, we first compared those who were bitten with those who were not (Table 1). Second, among those who were bitten, we compared the baseline characteristics of those who sought health care with those who did not, stratifying by type of locality (urban and peri-urban) (Table 2). For both analyses, we used a chi-square test to compare categorical variables with 10 or more observations per group, Fisher's exact test for categorical variables with fewer than 10 observations in any subgroup, and the Mann-Whitney $U$ test for age of the dog owner or interviewee, which did not follow a normal distribution and was truncated at 18 years. We also evaluated correlations between our continuous variables by type of locality. For distance to a healthcare facility, we used the shortest walking distance from the house to the closest healthcare facility, either health center or health post.

Our main objective was to identify spatial and social factors associated to seeking health care following a dog bite incident. To describe responses to dog bite incidents, we used categorical values: sought health care and did not seek health care. We ran univariable and multivariable logistic regression models and forced some test variables in the models previously found to be associated with seeking health care. ${ }^{34-43}$ We included the distance to the health facilities as a continuous and as a categorical variable in the models. We used $800 \mathrm{~m}, 1,000 \mathrm{~m}$, and $1,300 \mathrm{~m}$ as cutoff points to define houses that were close to and far from health facilities. Based on our univariable analysis, the following covariates were used to build the model: time living in the area, whether the bite was from the participant's own dog, distance to the closest healthcare facility, gender of the participant, and educational attainment. However, we also explored models via stepwise forward and backward selection including all the variables evaluated. We also applied principal component analysis to several variables including the distance to the closest healthcare facility, time living in the area, and age of the interviewee to reduce the dimensionality of the data while accounting for the collinearity. All data management and analysis were performed in $\mathrm{R}$ version 3.3.1 (R Development Core Team, 2016). 


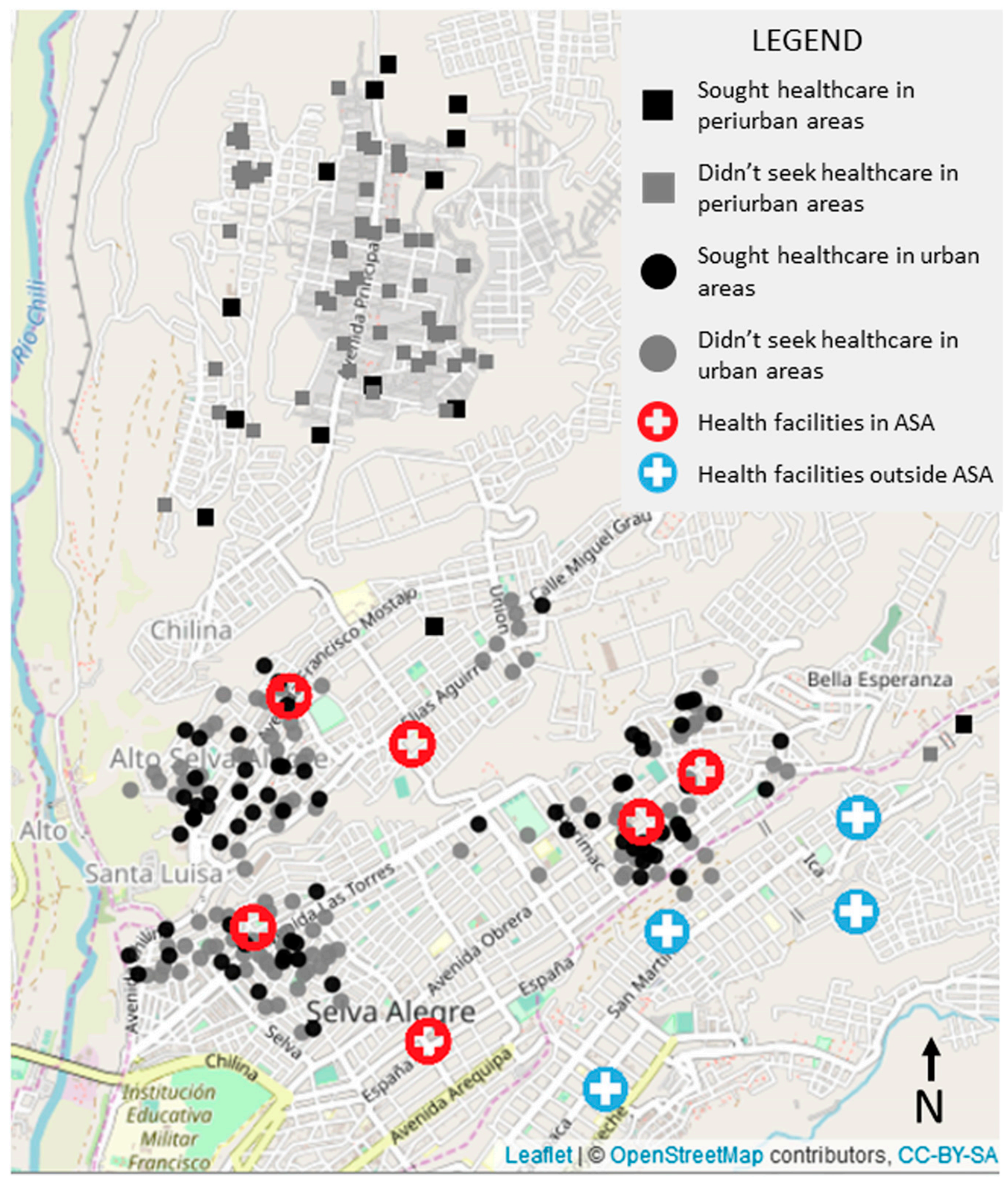

FIGURE 1. Bite cases and health facilities in urban and peri-urban localities of Arequipa City, Peru. Coordinates of cases have been jittered to protect confidentiality. This figure appears in color at www.ajtmh.org.

\section{RESULTS}

We visited 6,420 houses during the survey period. In all, 4,370 community members (each for a unique household) consented to participate in the study and were surveyed.
Overall 254 interviewees $(5.8 \%, 95 \% \mathrm{Cl}$ : 5.2-6.5) reported suffering a dog bite in the last 12 months: 184 in urban areas and 70 in peri-urban areas (Figure 1). The annual dog bite rate was $4.8 \%$ in urban areas and $12.4 \%$ in peri-urban areas (Table 1). The probability of being victim of a dog bite was 
TABLE 1

Association between demographic variables and being bitten or not being bitten by a dog in the Alto Selva Alegre district, Arequipa (2016)

\begin{tabular}{|c|c|c|c|}
\hline Variable & Bitten by a dog $(n=254)$ & Not bitten by a dog $(n=4016)$ & $P$-value \\
\hline \multicolumn{4}{|c|}{ Age of bitten people (years) } \\
\hline Median (IQR) & $38(26-53)$ & $40(28-53)$ & $0.242^{*}$ \\
\hline Mean (SD) & $40.49(16.17)$ & $41.61(15.93)$ & $0.282 \dagger$ \\
\hline Females (\%) & 61.8 & 66.8 & $0.026 \neq$ \\
\hline Educational attainment & & & $0.725 \S$ \\
\hline Primary school & 13.4 & 12.3 & \\
\hline Secondary school & 40.6 & 42.4 & \\
\hline Technical school & 20.1 & 21.3 & \\
\hline University & 25.2 & 23.5 & \\
\hline Illiterate & 0.8 & 0.5 & \\
\hline \multicolumn{4}{|c|}{ Total number of people in the house } \\
\hline Median (IQR) & $4(3-6)$ & $4(3-6)$ & $0.407^{\star}$ \\
\hline Mean (SD) & $4.49(2.11)$ & $4.63(2.26)$ & $0.293+$ \\
\hline \multicolumn{4}{|c|}{ Number of people $<18$ years in the house } \\
\hline Median (IQR) & $0(0-1)$ & $0(0-1)$ & $0.712^{*}$ \\
\hline Mean (SD) & $0.78(0.97)$ & $0.78(1.05)$ & $0.962 \dagger$ \\
\hline \multicolumn{4}{|c|}{ Number of children $<5$ years in the house } \\
\hline Median (IQR) & $0(0-1)$ & $0(0-1)$ & $0.947^{*}$ \\
\hline Mean (SD) & $0.48(0.77)$ & $0.47(0.76)$ & $0.965 \dagger$ \\
\hline \multicolumn{4}{|l|}{ Length of residence (years) } \\
\hline Median (IQR) & $15(5-25)$ & $16(6-26)$ & $0.356^{*}$ \\
\hline Mean (SD) & $18.16(14.17)$ & $17.39(14.25)$ & $0.420 \dagger$ \\
\hline Has dogs (\%) & 66.6 & 69.3 & $0.417 \ddagger$ \\
\hline \multicolumn{4}{|l|}{ Number of dogs } \\
\hline Median (IQR) & $1(0-2)$ & $1(0-2)$ & $0.213^{*}$ \\
\hline Mean (SD) & $1.35(1.38)$ & $1.24(1.25)$ & $0.195 \dagger$ \\
\hline
\end{tabular}

higher in women. Age of the participants (all adults), educational attainment, and the number of dogs at home were not associated with dog bite attacks. Other evaluated variables are given in Table 1.

Among those who suffered dog bites in urban areas, 39.1\% sought medical care at a healthcare facility after the bite incident, compared with $21.4 \%$ in peri-urban areas (overall medical seeking behavior $=34.3 \%, 95 \% \mathrm{Cl}:=28.7-40.3$ ). Variables associated with receiving medical attention after a dog bite were age of bitten adults, shortest route distances to the closest health post or center, time living in the area, and ownership of the dog that bit them (Figure 2). The probability of receiving medical attention decreased with greater distances between the house and the nearest health facility. A lower rate of seeking medical care was also associated with being bitten by one's own dogs rather than unknown dogs. $A$ higher probability of seeking medical attention was associated with a greater amount of time living in the area in the house and older age. Contrary to our expectations, we did not find an association between the vaccination status of the biting dog and seeking medical care. Association with the number of dogs in the house is unclear. Further information is given in in Table 2.

All six health facilities in ASA were located in the urban areas; there were no health facilities in the peri-urban area (Figure 1). Walking distance to the nearest health center or health post ranged from a few meters to $3.2 \mathrm{~km}$. A single health facility (C.S. Independencia) was the closest health facility for nearly half of the bitten adults (47.2\%, 120/254). For two participants, the closest health facility was in a different district. We found several notable differences between the characteristics of the households in urban and peri-urban areas (Figure 3). The distance from surveyed households to the nearest health post or center was significantly longer in peri-urban than urban areas. The number of people living in a household and time living in the area were higher in urban areas. Residents in peri-urban areas were more likely to have a dog at home and owned a higher number of dogs on average than residents in urban areas. Other variables associated with peri-urban versus urban households in ASA are detailed in Table 3.

There was a significant negative correlation between the distance from the house to the nearest health center and time living in the area $(P<0.001$, cor. -0.44$)$. As expected, there was a low to moderate positive correlation between the age of the surveyed person and time living in the area (0.34) and moderate positive correlation between the total number of people and the number of children younger than 18 years living in the house (0.41) and children younger than 5 years living in the house (0.5). In addition, weak negative correlation was found between the distance to the nearest health center and the total number of people in the house $(-0.21)$. This finding and our field observations suggest that overcrowding is not prevalent in peri-urban (and poor) areas of Arequipa, which goes counter to what is reported for marginal communities in other countries.

The best fitting model via forward and backward stepwise selection for all communities included the variables of interviewee's age, time living in the area, and the number of children younger than 5 years in the house and ownership and vaccination status of the dog that bit (Table 4). However, the set of statistically significant variables was different when the model was stratified by urban and peri-urban areas. For urban communities, only time living in the area and ownership of the 
TABLE 2

Association between demographic variables and adults seeking or not seeking healthcare after a dog bite incident in urban and peri-urban areas of Alto Selva Alegre district, Arequipa (2016)

\begin{tabular}{|c|c|c|c|c|c|c|}
\hline & \multicolumn{3}{|c|}{ Urban communities } & \multicolumn{3}{|c|}{ Peri-urban communities } \\
\hline & $\begin{array}{l}\text { Did not seek health } \\
\quad \text { care }(n=112)\end{array}$ & $\begin{array}{l}\text { Sought health care } \\
\qquad(n=72)\end{array}$ & $P$-value & $\begin{array}{l}\text { Did not seek health } \\
\text { care }(n=55)\end{array}$ & $\begin{array}{l}\text { Sought health care } \\
\qquad(n=15)\end{array}$ & $P$-value \\
\hline \multicolumn{7}{|c|}{$\begin{array}{l}\text { Shortest distance to health } \\
\text { facility (meters) }\end{array}$} \\
\hline Median (IQR) & $392.8(252.8-611.8)$ & $406.2(252.8-640.0)$ & $0.874^{*}$ & 2476.2 (2283.8-2792.2) & 2358.1 (1961.4-2504.6) & $0.047^{*}$ \\
\hline Mean (SD) & $448.8(239.1)$ & $447.9(224.6)$ & $0.978+$ & $2480.8(416.8)$ & $2230.4(464.1)$ & $0.073+$ \\
\hline \multicolumn{7}{|c|}{ Age of bitten people (years) } \\
\hline Median (IQR) & $37.5(25-51)$ & $47.5(32-60.25)$ & $0.004^{*}$ & $34(25.5-43)$ & $34(30-43)$ & $0.642^{*}$ \\
\hline Mean (SD) & $39.21(16.07)$ & $46.42(16.72)$ & $0.004 \dagger$ & $35.82(13.46)$ & 38.67 (16.59) & $0.547 \dagger$ \\
\hline Females (\%) & 63.4 & 59.7 & $0.730 \ddagger$ & 58.2 & 86.7 & $0.082 \ddagger$ \\
\hline \multicolumn{7}{|c|}{ Educational attainment (\%) } \\
\hline Primary school & 7.1 & 12.5 & $0.681 \S$ & 16.4 & 53.3 & $0.046 \S$ \\
\hline Secondary school & 40.2 & 34.7 & & 50.9 & 33.3 & \\
\hline Technical school & 22.3 & 20.8 & & 16.4 & 13.3 & \\
\hline University & 29.5 & 31.9 & & 14.5 & 0.0 & \\
\hline Illiterate & 0.9 & 0.0 & & 1.8 & 0.0 & \\
\hline \multicolumn{7}{|c|}{$\begin{array}{l}\text { Total number of people in } \\
\text { the house }\end{array}$} \\
\hline Median (IQR) & $4(3-6)$ & $4(3-6)$ & $0.752^{*}$ & $4(3-5)$ & $3(3-4.5)$ & $0.337^{*}$ \\
\hline Mean (SD) & $4.68(2.27)$ & $4.85(2.29)$ & $0.631 \dagger$ & $3.91(1.44)$ & $3.53(1.36)$ & $0.358 \dagger$ \\
\hline \multicolumn{7}{|c|}{ Number of people $<18$ years } \\
\hline \multicolumn{7}{|l|}{ in the house } \\
\hline Median (IQR) & $0(0-1)$ & $0(0-1)$ & $0.761^{*}$ & $1(0-1.5)$ & $0(0-1.5)$ & $0.522^{*}$ \\
\hline Mean (SD) & $0.77(1.01)$ & $0.67(0.82)$ & $0.459 \dagger$ & $0.96(1.07)$ & $0.73(0.88)$ & $0.401 \dagger$ \\
\hline \multicolumn{7}{|c|}{ Number of children $<5$ years } \\
\hline Median (IQR) & $0(0-1)$ & $0(0-1)$ & $0.533^{*}$ & $0(0-1)$ & $0(0-1)$ & $0.278^{*}$ \\
\hline Mean (SD) & $0.44(0.74)$ & $0.56(0.92)$ & $0.362 \dagger$ & $0.40(0.56)$ & $0.67(0.82)$ & $0.250 \dagger$ \\
\hline \multicolumn{7}{|c|}{ Length of residence (years) } \\
\hline Median (IQR) & $18(9-25)$ & $23(10-39.5)$ & $0.022^{*}$ & $5(3-10)$ & $8(6-11.5)$ & $0.084^{*}$ \\
\hline Mean (SD) & $19.01(13.51)$ & $24.69(15.72)$ & $0.015 \dagger$ & $6.42(4.67)$ & $8.53(4.16)$ & $0.106 \dagger$ \\
\hline Has dogs (\%) & 67.9 & 59.7 & $0.333 \ddagger$ & 81.8 & 80.0 & $1 \S$ \\
\hline \multicolumn{7}{|l|}{ Number of dogs } \\
\hline Median (IQR) & $1(0-2)$ & $1(0-2)$ & $0.114^{*}$ & $1(1-3)$ & $2(1-2)$ & $1^{*}$ \\
\hline Mean (SD) & 1.33 (1.33) & $1(1.09)$ & $0.068 \dagger$ & $1.76(1.70)$ & 1.67 (1.29) & $0.812 \dagger$ \\
\hline Bitten by own dog (\%) & 16.1 & 2.8 & $0.010 \ddagger$ & 20.0 & 0.0 & $0.105 \S$ \\
\hline $\begin{array}{l}\text { Bitten by vaccinated } \\
\text { dog }(\%)\end{array}$ & 28.8 & 34.7 & $0.498 \ddagger$ & 16.4 & 33.3 & $0.161 \S$ \\
\hline $\begin{array}{l}\text { IQR = interquartile range. } \\
{ }^{*} \text { Mann-Whitney U-test. } \\
\dagger T \text {-test. } \\
\neq \text { Chi-square test. } \\
\text { § Fisher's test. }\end{array}$ & & & & & & \\
\hline
\end{tabular}

dog that bit remained significant. By contrast, in peri-urban communities, time living in the area, the distance to the closest healthcare facility, and vaccination status of the dog that bit were not significant. Detailed results of the best fitting model are given in Table 4. These models also included gender and educational attainment of the bitten adult because they have shown to be important demographic characteristics for healthcare-seeking behavior.

\section{DISCUSSION}

Annual dog bite rates, the percentage of people bitten by dogs every year, vary geographically. In Latin America, Chile, Uruguay, Brazil, and Guyana have the lowest annual dog bite rates $(0.05-0.3 \%),{ }^{22,44}$ although Bolivia, Mexico and Haiti have reported the highest $(0.3-3.2 \%) .{ }^{22,45,46}$ Official rates in Peru for rabies-affected areas are $0.2 \%$ in Puno and $0.6 \%$ in Arequipa. We report a dog bite rate in peri-urban areas of Arequipa of $12.4 \%$, which is far higher than previously reported in any Latin American city. ${ }^{47-50}$ Rates in Arequipa are higher than those reported in Todos Santos, Guatemala; Guayaquil, Ecuador; Santa Cruz, Bolivia; Yucatán, Mexico
$(1.7 \%, 1.1 \%, 2.7 \%, 4.5 \%)$, all dog rabies-endemic areas when those numbers were reported. ${ }^{51-54}$

The high rate of dog bites in Arequipa is driven in large part by a disproportionate burden of dog bites in peri-urban areas of the city. We find a clear spatial disparity in dog bite burden: the risk of being bitten by dogs is 2.6 times higher in peri-urban areas than that in urban areas in the city of Arequipa, which is especially concerning for human rabies risk because dogs are less likely to be vaccinated against rabies in peri-urban than urban areas. ${ }^{55,56}$ One reason for the disproportionate rate of dog bites in peri-urban neighborhoods is a greater density of street dogs in peri-urban than urban areas of the city. ${ }^{41}$ There are several geographic and social correlates of street dog density in peri-urban areas. Geographically, there is more space for free-roaming dogs in peri-urban areas than densely populated urban areas. Another geographic feature is the presence of open waterways through the city, described as "highways" for street dogs to traverse the city. ${ }^{47}$ These natural or man-made structures are usually more accessible to dogs in the peri-urban areas. Houses in peri-urban areas are also built with cheaper materials than urban dwellings. Characteristic stone or brick fences and corrugated metal roofs are 
A

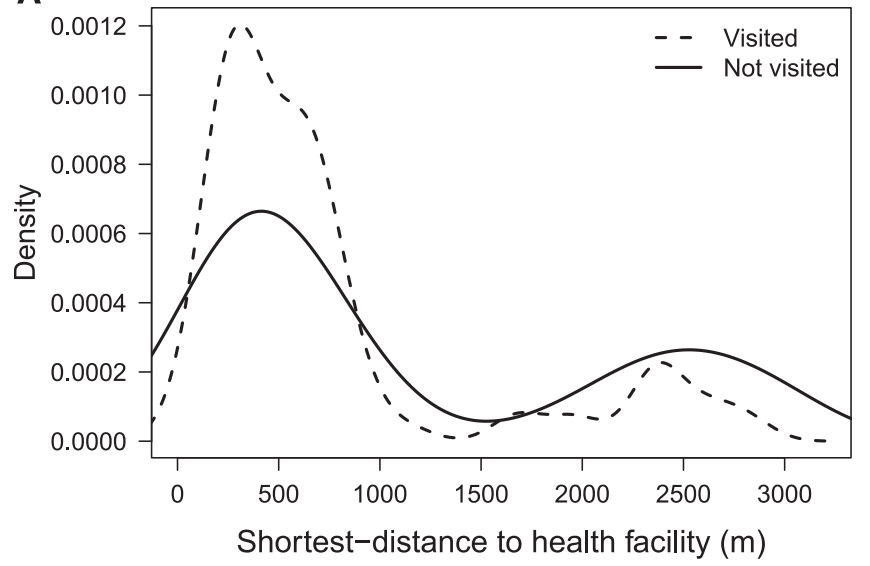

C

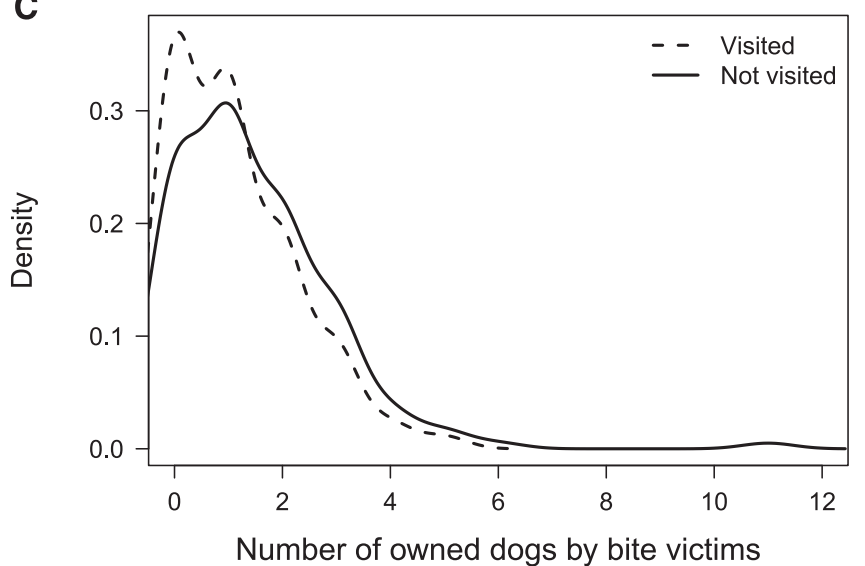

B

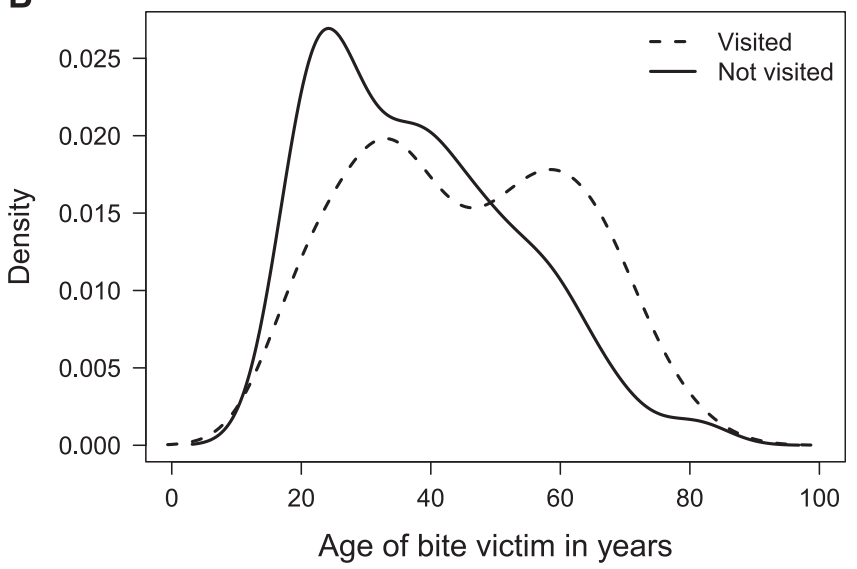

D

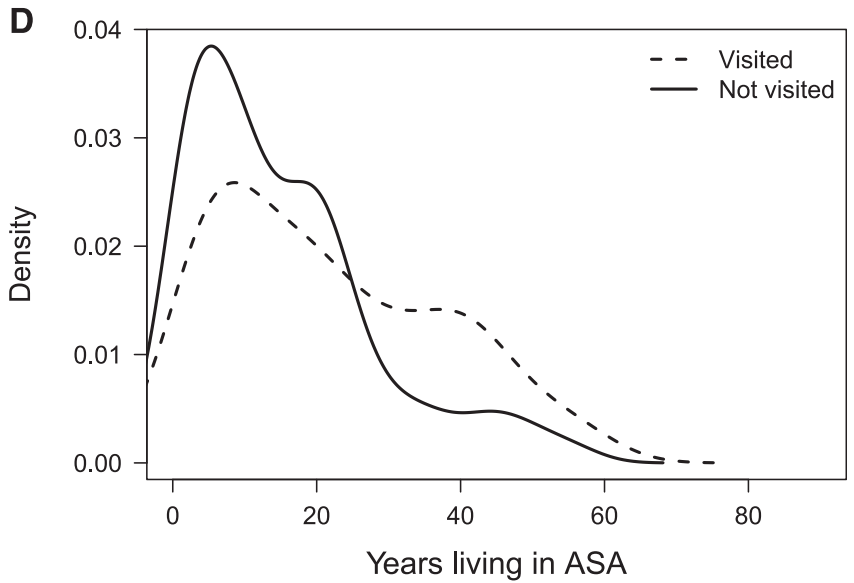

FIGURE 2. Care-seeking behavior of dog-bite victims by (A) distance from their house to the nearest health facility; (B) age of the dog-bite victim; (C) the number of dogs owned by the dog-bite victim; and (D) time living in the area.

not always effective at keeping pets inside or stray dogs out, especially if a female pet is in heat. ${ }^{41,48}$ But geographic characteristics of peri-urban Arequipa are only partially responsible for a higher dog density in peri-urban areas.

There are also unique social influences on dog density, which stem from the poverty of peri-urban areas. The cost of neutering or spaying a dog is significant, particularly in periurban areas where residents have a lower average household income. ${ }^{48}$ When pet dogs have puppies, those puppies may be left in the streets if they are not sold or adopted. Based on our qualitative studies, dog owners in Arequipa keep dogs for protection. ${ }^{48}$ This is especially true in peri-urban areas of the city, where there is more poverty and higher crime rates. ${ }^{41}$ Residents reported killing or abandoning dogs that were regarded as bad guard dogs, those that do not bark or bite. Clearly, there is a continuous artificial selection for more aggressive dogs in this area. Both geographic and social factors influence a higher density of street dogs, generally more aggressive dogs, a higher rate of unvaccinated dog bites and, therefore, a spatial disparity in human rabies risk across the city.

A "One Health" approach to rabies prevention in peri-urban Arequipa, which addresses rabies prevention in pets and humans, may inform more effective interventions to decrease spatial inequality in rabies risk. A "One Health" approach also helps explain more broadly the extremely high dog bite rate found in Arequipa city. In a separate study, ${ }^{49}$ we estimated the human-to-dog ratio in Arequipa and found it was 3.4-1, only counting owned dogs. This ratio suggests a very numerous dog population compared with other areas in Latin America. In the same study, we also found that $61 \%$ of dogs had free access to the street at least some hours a day, which, coupled with the human-to-dog ratio, indicates a high number of unrestricted dogs in the streets. A multidimensional intervention might be necessary to change the social drivers that lead to these dog ownership practices and prevent dog bites.

The trend of inequality in rabies risk in Arequipa continues after a person is bitten: people in peri-urban areas had a $45 \%$ lower probability of seeking medical care than people in urban areas. Initial and follow-up treatment for dog bites are essential in decreasing human rabies risk because the healthcare professionals can clean the wound, decreasing viral load, and can provide PEP, which is almost $100 \%$ effective in preventing the transmission of rabies when administered according to the schedule. ${ }^{9,50}$ More people in urban areas than peri-urban areas visit a health facility after a dog bite, and likely, some people who seek dog bite-related health care did not get treatment even after visiting a health center; thus, the percentages of people who receive rabies treatment may be even lower than the numbers of people who sought treatment. 
A

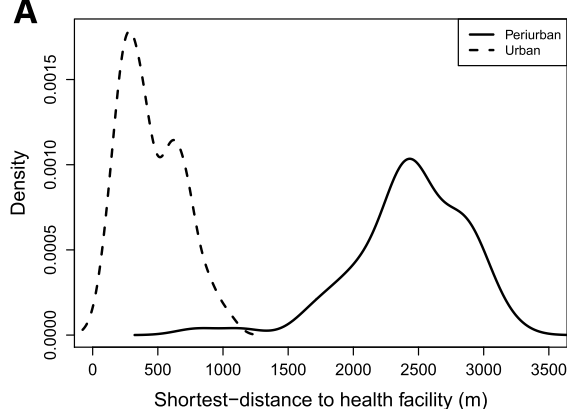

B

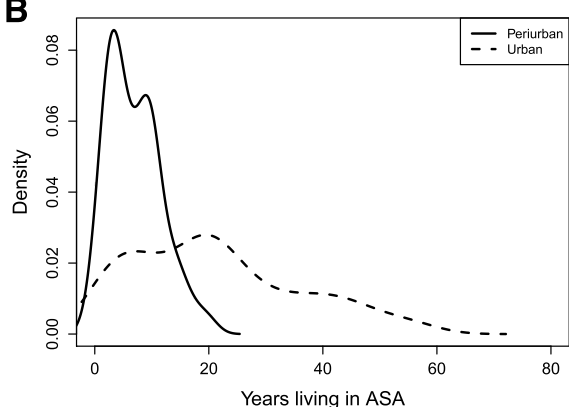

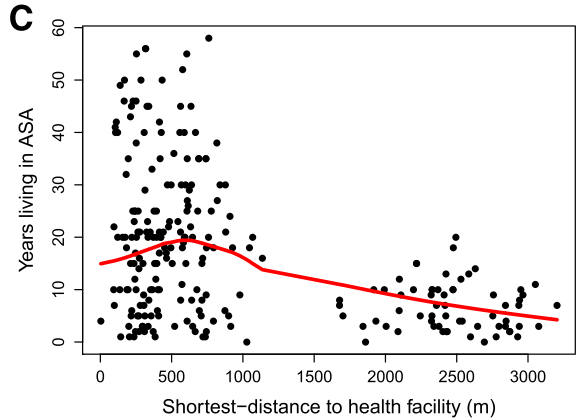

FIGURE 3. Associations and correlations between explanatory variables related to migratory patterns in urban and peri-urban localities: (A) distance to the nearest health facility by locality type (urban/periurban); (B) time living in the area by locality type (urban/periurban); and (C) distance to the nearest health facility and time living in the area. This figure appears in color at www.ajtmh.org.

The distance to the nearest health facility is a particularly important barrier to medical treatment in the peri-urban areas of the ASA district, where the average distance to the nearest health center or health post to people bitten by a dog is 2,427 meters as compared with 449 meters in urban areas of the district. Furthermore, newly developed communities in periurban areas are often served by health posts rather than larger health centers. In a previous study of another peri-urban area of Arequipa, focus group participants expressed that a shortage of materials such as PEP vaccines discourages community members from seeking rabies-related health care there. ${ }^{48}$

Our findings align with those of previous studies, which have reported an association between the distance to health facilities and decreased frequency of treatment and prevention for a variety of infectious and noninfectious diseases. ${ }^{37,41-43,55-58}$ The distance to healthcare facilities is also related to worse health outcomes, especially in rural areas because sick people receive delayed or no medical attention at all. ${ }^{40,59-66}$ Specifically, in the case of rabies, increased distance to a health facility has been associated with a delay in PEP uptake in Delhi and northwestern Tanzania. ${ }^{67,68}$ In a study of districts throughout Tanzania, there was also a greater number of deaths from rabies the farther away people lived from their closest health facility. ${ }^{68}$

The time required to travel to a medical facility can be an especially salient barrier for people living in peri-urban areas. Many of them work informal jobs, ${ }^{41,48}$ where missing work may mean missing a day's wages or even putting their employment at risk. ${ }^{69}$ In addition, people who have lived in their homes for fewer years are significantly less likely to seek medical health care after a dog bite in all of ASA. The same trend was observed in the model stratified by area type, but it was not significant in the peri-urban area most likely because of the reduced sample size. This finding indicates another way in which community members living in peri-urban areas are at a disadvantage in receiving medical care. People who have lived in their neighborhoods for longer have likely learned the medical and social services available to them and use them with more ease. Therefore, a high rate of recent migration in peri-urban neighborhoods could represent another influence on low rates of rabies treatment in peri-urban areas of ASA.

In addition to providing PEP and wound care that can mitigate human rabies transmission, a medical follow-up for dog bites at health centers and health posts is important for data collection. ${ }^{70}$ Following the detection of rabid dogs in Arequipa city in 2015, the official number of dog bites in the Arequipa region increased from 2,599 in 2014 (annual bite rate $=0.2 \%$ ) to 6,621 in $2015(0.5 \%)$ and 10,332 in $2016(0.8 \%) .{ }^{71}$ The difference between the findings from our door-to-door survey and official public health department metrics implies significant underreporting of dog bites, particularly in peri-urban areas of Arequipa. Underreporting is likely due to a number of barriers related to lack of access to health care, some of which are analyzed in our study. However, these barriers to seek medical care do not fully explain the extreme differences between the dog bite rates we found and the rates officially reported. It is possible that data management activities, such as collecting, entering, centralizing, and sharing data, are also sources of underreporting. Despite the fact that no native human rabies cases have been detected in Arequipa to date, low rates of reporting during medical follow-ups entail a risk for under-detection of human cases. Missing cases have negative consequences for national programs that control outbreaks and provide preventive measures. ${ }^{70,72-75}$ We suggest that spatial inequality obscures underreporting because several factors associated with not receiving a medical follow-up or reporting bites are concentrated in peri-urban areas.

Findings should be understood within the context of some limitations. The percentage of people bitten by dogs represents only adults in peri-urban and urban areas of ASA. Children were excluded because adults in the household make decisions about medical treatment. Although we did not analyze children's data, in the last year, 3.5\% (154/4,370) of houses interviewed had children bitten by a dog that they did not own. We did not ask about children bitten by dogs that they did own. Because children have made up a disproportionate percentage of dog bite victims $^{76-79}$ and human rabies cases ${ }^{80,81}$ in previous studies, future studies of rabies risk in Arequipa should include children to gain a fuller understanding of rabies risk in peri-urban Arequipa. Another limitation is that the data are self-reported in door-todoor surveys. Thus, data may be distorted by participants' memories or social desirability bias, when participants provide the answer that they think the interviewer or other community members view most favorably.

Access to health care is, in many ways, the product of urbanization. The construction of health facilities in newly urbanizing areas often lags behind the population of these areas. These new facilities generally provide basic services and offer treatment for frequent health problems. ${ }^{28}$ Initiatives that focus 
TABLE 3

Association between demographic variables and residence in urban versus peri-urban areas of Alto Selva Alegre district, Arequipa (2016)

\begin{tabular}{|c|c|c|c|}
\hline & Peri-urban $(n=70)$ & Urban $(n=184)$ & $P$-value \\
\hline \multicolumn{4}{|c|}{ Shortest distance to the health facility (meters) } \\
\hline Median (IQR) & 2439.6 (2224.7-2771.9) & $398.4(252.8-618.4)$ & $<0.001^{*}$ \\
\hline Mean (SD) & $2427.2(436.3)$ & $448.5(233.0)$ & $<0.001 \dagger$ \\
\hline \multicolumn{4}{|l|}{ Age of bitten people (years) } \\
\hline Median (IQR) & $34(26-43)$ & $40(27-56)$ & $0.02^{*}$ \\
\hline Mean (SD) & $36.43(14.11)$ & $42.03(16.66)$ & $0.008 \dagger$ \\
\hline Females (\%) & 64.3 & 62.0 & $0.843 \ddagger$ \\
\hline \multicolumn{4}{|l|}{ Educational attainment (\%) } \\
\hline Primary school & 24.3 & 9.2 & $0.001 \S$ \\
\hline Secondary school & 47.1 & 38 & \\
\hline Technical school & 15.7 & 21.7 & \\
\hline University & 11.4 & 30.4 & \\
\hline Illiterate & 1.4 & 0.5 & \\
\hline \multicolumn{4}{|c|}{ Total number of people in the house } \\
\hline Median (IQR) & $4(3-5)$ & $4(3-6)$ & $0.007^{\star}$ \\
\hline Mean (SD) & $3.83(1.42)$ & $4.74(2.27)$ & $<0.001 \dagger$ \\
\hline \multicolumn{4}{|c|}{ Number of people $<18$ years in the house } \\
\hline Median (IQR) & $1(0-1.75)$ & $0(0-1)$ & $0.175^{\star}$ \\
\hline Mean (SD) & $0.91(1.03)$ & $0.73(0.94)$ & $0.191 \dagger$ \\
\hline \multicolumn{4}{|c|}{ Number of children $<5$ years in the house } \\
\hline Median (IQR) & $0(0-1)$ & $0(0-1)$ & $0.609^{*}$ \\
\hline Mean (SD) & $0.46(0.63)$ & $0.48(0.82)$ & $0.783+$ \\
\hline \multicolumn{4}{|l|}{ Length of residence (years) } \\
\hline Median (IQR) & $7(3-10)$ & $20(9.5-30)$ & $<0.001^{*}$ \\
\hline Mean (SD) & $6.91(4.62)$ & $21.28(14.66)$ & $<0.001 \dagger$ \\
\hline Has dogs (\%) & 81.4 & 64.7 & $0.015 \ddagger$ \\
\hline \multicolumn{4}{|l|}{ Number of dogs } \\
\hline Median (IQR) & $1.50(1-2.75)$ & $1(0-2)$ & $0.003^{*}$ \\
\hline Mean (SD) & $1.74(1.61)$ & $1.2(1.25)$ & $0.013+$ \\
\hline Bitten by own dog (\%) & 15.7 & 10.9 & $0.401 \neq$ \\
\hline Bitten by vaccinated dog (\%) & 20.0 & 31.1 & $0.108 \ddagger$ \\
\hline
\end{tabular}

on expanding and modernizing peri-urban health facilities could decrease spatial inequality in rabies risk. There is also evidence that community health worker programs that provide education and case management have had positive outcomes in the setting of other diseases. ${ }^{82-84}$ The implementation of a community health worker program that leverages the social capital in the neighborhoods to cultivate rabies awareness, detect bitten people, track dogs that bite, and promote adherence to PEP would be a strategy with a good potential to reduce risk of dog rabies transmission to humans.

Our study shows that there is substantial underreporting of dog bites throughout Arequipa, particularly in peri-urban areas. We also find that in areas that are just blocks apart, many risk factors for human rabies, such as the presence of free-roaming dogs, incidence of dog rabies, dog bite rates, and access to health services, vary greatly. In peri-urban areas of Arequipa, residents have a higher rate of dog bites likely because of the high density of free-roaming dogs. Then, they are less likely to receive a medical follow-up, where wound care and PEP are provided and reporting often occurs. We show that people are more likely to receive follow-up care the closer they are to a medical center or post and discuss how medical infrastructure in peri-urban areas often lag behind urban areas of the city. Therefore, future interventions to address rabies risk in Arequipa should focus on addressing the specific needs of peri-urban areas, communities that have historically been overlooked in academic studies because they do not fit neatly into an urban-rural dichotomy. ${ }^{85,86}$

TABLE 4

Demographic variables associated with seeking medical healthcare after a dog bite in urban and peri-urban areas of Alto Selva Alegre district, Arequipa, 2016. Forced variables in the multivariate logistic regression included gender and educational attainment of the bitten adult

\begin{tabular}{|c|c|c|c|c|c|c|c|c|c|}
\hline & \multicolumn{3}{|c|}{ All communities } & \multicolumn{3}{|c|}{ Urban communities } & \multicolumn{3}{|c|}{ Peri-urban communities } \\
\hline & OR & $95 \% \mathrm{Cl}$ & $P$-value & OR & $95 \% \mathrm{Cl}$ & $P$-value & OR & $95 \% \mathrm{Cl}$ & $P$-value \\
\hline 1 decade less time living in the area & 0.73 & $(0.59,0.92)$ & 0.008 & 0.75 & $(0.59,0.94)$ & 0.012 & 0.49 & $(0.12,1.99)$ & 0.319 \\
\hline Bite by own dog & 0.11 & $(0.02,0.48)$ & 0.003 & 0.14 & $(0.03,0.67)$ & 0.013 & 0 & $(0$, inf $)$ & 0.993 \\
\hline $\begin{array}{l}\text { Distance to the closest healthcare } \\
\text { facility }(\mathrm{m})\end{array}$ & 1 & $(0.999,1)$ & 0.217 & 1 & $(0.999,1.001)$ & 0.982 & 0.999 & $(0.998,1.001)$ & 0.264 \\
\hline Gender (female) & 1.35 & $(0.73,2.50)$ & 0.336 & 1.12 & $(0.57,2.19)$ & 0.751 & 2.22 & $(0.38,12.94)$ & 0.375 \\
\hline $\begin{array}{l}\text { Educational attainment (one level } \\
\text { increase) }\end{array}$ & 0.95 & $(0.71,1.27)$ & 0.738 & 1.074 & $(0.78,1.48)$ & 0.66 & 0.54 & $(0.20,1.44)$ & 0.219 \\
\hline
\end{tabular}


Received March 9, 2020. Accepted for publication May 25, 2020.

Published online July 13, 2020.

Acknowledgments: Micaela De la Puente-León is a doctoral student studying an Epidemiological Research Doctorate at Universidad Peruana Cayetano Heredia under FONDECYT/CIENCIACTIVA scholarship EF033-235-2015 and supported by training grant D43 TW007393 awarded by the Fogarty International Center of the US National Institutes of Health.

Financial support: This work was supported by the Eunice Kennedy Shriver National Institute of Child Health and Human Development (Grant no. R01 HD075869). R. C. N. was partially supported by the National Institute of Allergy and Infectious Diseases (Grant no. 1K01Al139284). The funders had no role in study design, data collection and analysis, decision to publish, or preparation of the manuscript.

Authors' addresses: Micaela De la Puente-León and Amparo M. Toledo, Zoonotic Disease Research Laboratory, One Health Unit, School of Public Health and Administration, Universidad Peruana Cayetano Heredia, Arequipa, Perú, E-mails: virginia.de.la.puente@ upch.pe and amparomarisol@gmail.com. Michael Z. Levy, Julianna Shinnick, and Ricardo Castillo-Neyra, Department of Biostatistics, Epidemiology and Informatics, University of Pennsylvania, Philadelphia, PA, E-mails: mzlevy@pennmedicine.upenn.edu, shinnick@ upenn.edu, and cricardo@upenn.edu. Sergio Recuenco, Centro de Investigaciones Tecnológicas, Biomédicas y Medioambientales, Universidad Nacional Mayor de San Marcos, Lima, Perú, E-mail: sergio.recuenco@gmail.com.

\section{REFERENCES}

1. Bayer AM, Hunter GC, Gilman RH, Cornejo JG, Bern C, Levy MZ, 2009. Chagas disease, migration and community settlement patterns in Arequipa, Peru. PLoS Negl Trop Dis 3: e567.

2. Pedersen D, Tremblay J, Errázuriz C, Gamarra J, 2008. The sequelae of political violence: assessing trauma, suffering and dislocation in the Peruvian highlands. Soc Sci Med 67: 205-217.

3. Instituto Nacional de Estadística e Informática, 1995. Las Migraciones Internas en el Perú: 1981-1993. Available at: https:// www.inei.gob.pe/media/MenuRecursivo/publicaciones_digitales/ Est/Lib0018/capi3001.htm. Accessed January 23, 2020.

4. Duranton G, Puga D, 2014. The growth of cities. Handbook of Economic Growth Vol II. New York, NY: Elsevier, 781-853.

5. Levy MZ et al., 2014. Urbanization, land tenure security and vector-borne Chagas disease. Proc Biol Sci 281: e20141003.

6. Lobao L, Hooks G, Tickamyer AR, 2007. The Sociology of Spatial Inequality. Albany, NY: SUNY Press.

7. Castillo-Neyra R, Zegarra E, Monroy Y, Bernedo R, CornejoRosello I, Paz-Soldan V, Levy M, 2017. Spatial association of canine rabies outbreak and ecological urban corridors, Arequipa, Peru. Trop Med Infect Dis 2: 38.

8. Dirección General de Epidemiología, 2015. Situación de la rabia Urbana en el Perú. Año 2015, hasta la SE 14. Boletín Epidemiológico del Perú 24: 300-302.

9. World Health Organization, 2013. WHO expert consultation on rabies. Second report. World Health Organ Tech Rep Ser 982: $1-139$.

10. Dirección General de Epidemiología, 2016. Reporte de vigilancia de rabia, Perú 2016 (SE 52). Boletín Epidemiol Perú 25: 1187-1188.

11. Bronnert J, Wilde H, Tepsumethanon V, Lumlertdacha B, Hemachudha T, 2007. Organ transplantations and rabies transmission. J Travel Med 14: 177-180.

12. Vora NM et al., 2013. Raccoon rabies virus variant transmission through solid organ transplantation. JAMA 310: 398-407.

13. Gerencia Regional de Salud Arequipa, 2015. Alerta epidemiológica ante la identificación de casos de rabia canina en Arequipa y riesgo de rabia urbana humana. Boletín Epidemiol (Arequipa) 1: 1. Arequipa: Gerencia Regional de Salud Arequipa.

14. Gerencia Regional de Salud Arequipa, 2016. Mordedura de Perro. Boletín Epidemiol (Arequipa) 12: 10. Arequipa: Gerencia Regional de Salud Arequipa.
15. Dirección General de Epidemiología, 2016. Situación de la rabia Arequipa, año 2015 SE 52. Boletín Epidemiol Perú 25: 22-24.

16. Dirección General de Epidemiología, 2017. Reporte de vigilancia de rabia, Perú 2017. Boletín Epidemiol Perú 26: 1630-1632.

17. Dirección General de Epidemiología, 2018. Situación epidemiológica de rabia en el Perú, 2018. Boletín Epidemiol Perú 27: 1258-1262.

18. Dirección General de Epidemiología, 2017. Boletín Epidemiol Perú 26: 636-640.

19. Fishbein DB, 1991. Rabies in humans. The Natural History of Rabies, 2nd edition. Boca Raton, FL: CRC Press, 519-549.

20. Hemachudha T, Laothamatas J, Rupprecht CE, 2002. Human rabies: a disease of complex neuropathogenetic mechanisms and diagnostic challenges. Lancet Neurol 1: 101-109.

21. Cleaveland S, Hampson K, 2007. Rabies elimination research: juxtaposing optimism, pragmatism and realism. Proc $R$ Soc $B$ 284: e20171880.

22. Hampson $\mathrm{K}$ et al., 2015. Estimating the global burden of endemic canine rabies. PLoS Negl Trop Dis 9: e0003709.

23. Hampson K, Dushoff J, Cleaveland S, Haydon DT, Kaare M, Packer C, Dobson A, 2009. Transmission dynamics and prospects for the elimination of canine rabies. PLoS Biol 7: e1000053.

24. Mindekem R, Lechenne MS, Naissengar KS, Lechenne MS, 2017. Cost description and comparative cost efficiency of postexposure prophylaxis and canine mass vaccination against rabies in N'Djamena, Chad. Front Vet Sci 4: 38.

25. Yoder J, Younce E, Lankester F, Palmer GH, 2019. Healthcare demand in response to rabies elimination campaigns in Latin America. PLoS Negl Trop Dis 13: e0007630.

26. Rupprecht CE, Hanlon CA, Slate D, 2006. Control and prevention of rabies in animals: paradigm shifts. Dev Biol (Basel) 125: 103-111.

27. Fooks AR, Banyard AC, Horton DL, Johnson N, McElhinney LM, Jackson AC, 2014. Current status of rabies and prospects for elimination. Lancet 384: 1389-1399.

28. Ministerio de Salud del Perú, 2017. Norma Técnica de Salud para la Vigilancia, Prevención y Control de la Rabia Humana en el Perú. Lima, Peru: Ministerio de Salud del Perú.

29. Schneider MC, Belotto A, Adé MP, Hendrickx S, Leanes LF, Rodrigues MJ, Medina G, Correa E, 2007. Current status of human rabies transmitted by dogs in Latin America. Cad Saude Publica 23: 2049-2063.

30. Franka R, Smith TG, Dyer JL, Wu X, Niezgoda M, Rupprecht CE, 2013. Current and future tools for global canine rabies elimination. Antiviral Res 100: 220-225.

31. Municipalidad Alto Selva Alegre, 2018. Memorial Anual 2017. Available at: http://munialtoselvaalegre.gob.pe/transparencia/ infor_presupuestal/memoria_anual_2017.pdf. Accessed February 5, 2020.

32. Manning S, Rupprecht CE, Fishbein DB, 2008. Human Rabies Prevention-United States, 2008. Available at: https://www.cdc. $\mathrm{gov} / \mathrm{mmwr} / \mathrm{preview} / \mathrm{mmw}$ rhtml/rr5703a1.htm. Accessed February 4, 2020.

33. Crickard P, 2014. Leaflet, Js Essentials. Birmingham, England: Packt Publishing.

34. Tschopp R, Bekele S, Aseffa A, 2016. Dog demography, animal bite management and rabies knowledge-attitude and practices in the awash basin, eastern Ethiopia. PLoS Negl Trop Dis 10: e0004471.

35. Yan S, Chen Y, Ye W, Chen F, Li L, 2019. Characteristics and factors associated with post-exposure prophylaxis (PEP) treatment of dog and cat bites among left-behind children: a cross-sectional study in two cities of China. BMJ Open 9: e024764.

36. Bourne PA, Eldemire-shearer D, Mcgrowder D, Crawford T, 2009. Examining health status of women in rural, peri-urban and urban areas in Jamaica. N Am J Med Sci 1: 256-271.

37. Guagliardo MF, 2004. Spatial accessibility of primary care: concepts, methods and challenges. Int $J$ Health Geogr 3: 3.

38. Kelly C, Hulme C, Farragher T, Clarke G, 2016. Are differences in travel time or distance to healthcare for adults in global north countries associated with an impact on health outcomes? A systematic review. BMJ Open 6: e013059. 
39. Kyriopoulos I-I, Zavras D, Skroumpelos A, Mylona K, Athanasakis $\mathrm{K}$, Kyriopoulos J, 2014. Barriers in access to healthcare services for chronic patients in times of austerity: an empirical approach in Greece. Int J Equity Health 13: 54.

40. Starfield B, Shi L, Macinko J, 2005. Contribution of primary care to health systems and health. Milbank Q 83: 457-502.

41. Castillo-Neyra R, Brown J, Borrini K, Arevalo C, Levy MZ, Buttenheim A, Hunter GC, Becerra V, Behrman J, Paz-Soldan VA, 2017. Barriers to dog rabies vaccination during an urban rabies outbreak: qualitative findings from Arequipa, Peru. PLoS Negl Trop Dis 11: e0005460.

42. Fone DL, Christie S, Lester N, 2006. Comparison of perceived and modelled geographical access to accident and emergency departments: a cross-sectional analysis from the Caerphilly health and social needs study. Int $J$ Health Geogr 5: 16.

43. Jacobs B, Ir P, Bigdeli M, Annear PL, Van Damme W, 2012. Addressing access barriers to health services: an analytical framework for selecting appropriate interventions in lowincome Asian countries. Health Policy Plan 27: 288-300.

44. Silva AF, Costa EC, 2016. Acidentes Rábicos: Um Olhar Sobre os Fatores Desencadeantes e seu Mapeamento Territorial em um Município do Estado do Ceará. Redenção, Brazil: Curso de Enfermagem, Instituto de Ciências da Saúde, Universidade da Integração Internacional da Lusofonia Afro-brasileira, Acarape.

45. Departamento de Estadísticas e Información de Salud. Ministerio de Salud de Chile, 2017. Estadísticas de Mordeduras Caninas. Available at: http://www.deis.cl/estadisticas-de-enfermedadesde-notificacion-obligatoria/. Accessed April 14, 2020.

46. Schildecker $S$ et al., 2017. Dog ecology and barriers to canine rabies control in the Republic of Haiti, 2014-2015. Transbound Emerg Dis 64: 1433-1442.

47. Borrini-Mayor K, Sanchez RS, Ancca-Juárez J, Tito DP, Velásquez JY, Navarro OC, Castillo-Neyra R, Levy MZ, 2012. Efecto de la saliva de Triatoma infestans en la duración de la parasitemia de Trypanosoma cruzi en cuyes. VIII Congreso Peruano de Parasitología "Dr. Eleazar Córdova Benzaquen". Trujillo, Peru.

48. Castillo-Neyra R, Buttenheim AM, Brown J, Ferrara JF, ArevaloNieto C, Borrini-Mayorí K, Levy MZ, Becerra V, Paz-Soldan VA, 2020. Behavioral and Structural Barriers to Human PostExposure Prophylaxis and Other Preventive Practices During A Canine Rabies Epidemic. medRxiv. [Preprint]. Available at: https://www.medrxiv.org/content/10.1101/2020.01.16. 20016394v1. Accessed April 14, 2020.

49. Castillo-Neyra R, Toledo AM, Arevalo-Nieto $C$, MacDonald $H$, De la Puente-León M, Naquira-Velarde C, Paz-Soldan VA, Buttenheim AM, Levy MZ, 2019. Socio-spatial heterogeneity in participation in mass dog rabies vaccination campaigns, Arequipa, Peru. PLoS Negl Trop Dis 13: e0007600.

50. Tarantola A, Tejiokem MC, Briggs DJ, 2019. Evaluating new rabies post-exposure prophylaxis (PEP) regimens or vaccines. Vaccine 37: A88-A93.

51. Ortega-Pacheco A, Rodríguez-Buenfil JC, Bolio-González ME, Sauri-Arceo $\mathrm{CH}$, Jiménez-Coello $\mathrm{M}$, Forsberg CL, 2015. A survey of dog populations in urban and rural areas of Yucatan, Mexico. Anthrozoös 20: 261-274.

52. Suzuki K, Pereira JAC, Frías LA, López R, Mutinelli LE, Pons ER, 2008. Rabies-vaccination coverage and profiles of the owneddog population in Santa Cruz de la Sierra, Bolivia. Zoonoses Public Health 55: 177-183.

53. Lunney M, Jones A, Stiles E, Waltner-Toews D, 2011. Assessing human-dog conflicts in Todos Santos, Guatemala: bite incidences and public perception. Prev Vet Med 102: 315-320.

54. Calderón-Gonzáles JL, 2019. Mordeduras por Derros en la Ciudad de Guayaquil-Ecuador: un Riesgo Zoonótico. Barcelona, Spain: Facultad de Veterinaria, Universidad Autónoma de Barcelona.

55. O'Donnell O, 2007. Access to health care in developing countries: breaking down demand side barriers. Cad Saude Pública 23: 2820-2834.

56. Turnbull J, Martin D, Lattimer V, Pope C, Culliford D, 2008. Does distance matter? Geographical variation in GP out-of-hours service use: an observational study. $\mathrm{Br} J$ Gen Pract 58: 471-477.
57. Jordan H, Roderick P, Martin D, Barnett S, 2004. Distance, rurality and the need for care: access to health services in South West England. Int J Health Geogr 3: 21

58. Kiwanuka SN, Ekirapa EK, Peterson S, Okui O, Rahman MH, Peters D, Pariyo GW, 2008. Access to and utilisation of health services for the poor in Uganda: a systematic review of available evidence. Trans R Soc Trop Med Hyg 102: 1067-1074.

59. Becher H, Müller O, Jahn A, Gbangou A, Kynast-wolf G, Kouyaté $B, 2004$. Risk factors of infant and child mortality in rural Burkina Faso. Bull World Health Organ 82: 265-273.

60. Den Broeck JV, Eeckels R, Massa G, 1996. Maternal determinants of child survival in a rural African community. Int $J$ Epidemiol 25: 998-1004.

61. Ensor T, Cooper S, 2004. Overcoming barriers to health service access and influencing the demand side through purchasing. The International Bank for Reconstruction, Development. Washington, DC: The World Bank, 78.

62. Joshi R, Jan S, Wu Y, Macmahon S, 2008. Global inequalities in access to cardiovascular health care. Our greatest challenge. JAAC 52: 1817-1825.

63. Magnani RJ, Rice JC, Mock NB, Abdoh AA, Mercer DM, Tankari K, 1996. The impact of primary health care services on under-five mortality in rural Niger. Int J Epidemiol 25: 568-577.

64. Mayxay M et al., 2013. Respiratory illness healthcare-seeking behavior assessment in the Lao People's Democratic Republic (Laos). BMC Public Health 13: 144.

65. Mwaura LW, Wandibba S, Olungah CO, 2017. Effect of distance on access to health services among women with type 2 diabetes in a rural community in Kenya. AJDM 25: 2-4.

66. Pierce C, 2007. Distance and access to health care for rural women with heart failure. Online J Rural Nurs Health Care 7: 27-34.

67. Joseph J, N S, Khan AM, Rajoura OP, 2013. Determinants of delay in initiating post-exposure prophylaxis for rabies prevention among animal bite cases: hospital based study. Vaccine 32: 74-77.

68. Hampson K, Dobson A, Kaare M, Dushoff J, Magoto M, Sindoya E, Cleaveland S, 2008. Rabies exposures, post-exposure prophylaxis and deaths in a region of endemic canine rabies. PLOS Negl Trop Dis 2: e339.

69. Machado R, 2014. The informal economy in Peru: magnitude and determinants. Apuntes 41: 197-233.

70. Gibbons CL et al., 2014. Measuring underreporting and underascertainment in infectious disease datasets: a comparison of methods. BMC Public Health 14: 147.

71. Lohmann J, Muula AS, Houlfort N, De Allegri M, 2018. How does performance-based financing affect health workers' intrinsic motivation? A self-determination theory-based mixed-methods study in Malawi. Soc Sci Med 208: 1-8.

72. Burton DC, Flannery B, Onyango B, Larson C, Alaii J, Zhang X, Hamel MJ, Breiman RF, Feikin DR, 2011. Healthcare-seeking behaviour for common infectious disease-related illnesses in rural Kenya: a community-based house-to-house survey. $J$ Health Popul Nutr 29: 61-70.

73. Hitchcock P, Chamberlain A, Van Wagoner M, Inglesby TV, O'Toole T, 2007. Challenges to global surveillance and response to infectious disease outbreaks of international importance. Biosecur Bioterror 5: 206-227.

74. Moss R, Zarebski AE, Carlson SJ, McCaw JM, 2019. Accounting for healthcare-seeking behaviours and testing practices in realtime influenza forecasts. Trop Med Infect Dis 4: 12.

75. Wójcik OP, Brownstein JS, Chunara R, Johansson MA, 2014. Public health for the people: participatory infectious disease surveillance in the digital age. Emerg Themes Epidemiol 11: 7.

76. Dhand NK, Ward MP, 2011. Human rabies post exposure prophylaxis in Bhutan, 2005-2008: trends and risk factors. Vaccine 29: 4094-4101.

77. Sudarshan MK, Mahendra BJ, Madhusudana SN, Ashwoath Narayana DH, Rahman A, Rao NSN, X-Meslin F, Lobo D, Ravikumar K, Gangaboraiah, 2006. An epidemiological study of animal bites in India: results of a WHO sponsored national multicentric rabies survey. J Commun Dis 38: 32-39.

78. Kent SJW, Naicker B, Wood DR, 2012. Demographics and management of dog bite victims at a level two hospital in KwaZulu-Natal. S Afr Med J 102: 845-847.

79. Kabeta T, Deresa B, Tigre W, Ward MP, Mor SM, 2015. Knowledge, attitudes and practices of animal bite victims attending 
an anti-rabies health center in Jimma town, Ethiopia. PLoS Negl Trop Dis 9: e0003867.

80. Dodet B et al., 2008. Rabies awareness in eight Asian countries. Vaccine 26: 6344-6348.

81. Sriaroon C, Sriaroon P, Daviratanasilpa S, Khawplod P, Wilde H, 2006. Retrospective: animal attacks and rabies exposures in Thai children. Travel Med Infect Dis 4: 270-274.

82. Mitnick $\mathrm{C}$ et al., 2003. Community-based therapy for multidrugresistant tuberculosis in Lima, Peru. $N$ Engl $J$ Med 348: 119-128.

83. Paintain LS, Willey B, Kedenge S, Sharkey A, Kim J, Buj V, Webster J, Schellenberg D, Ngongo N, 2014. Community health workers and stand-alone or integrated case management of malaria: a systematic literature review. Am J Trop Med Hyg 91: 461-470.

84. Brenner JL et al., 2011. Can volunteer community health workers decrease child morbidity and mortality in southwestern Uganda? An impact evaluation. PLoS One 6: e27997.

85. Simon D, 2008. Urban environments: issues on the peri-urban fringe. Annu Rev Environ Resour 33: 167-185.

86. Marshall F, Waldman L, MacGergor H, Mehta L, Randhawa P, 2009. On the edge of sustainability: perspectives on peri-urban dynamics. STEPS Working Paper 35, Brighton, England: STEPS Centre. 